\title{
Ausência de desgaste agudo da musculatura esquelética e cardíaca em atletas amadores de triathlon
}

\author{
Absence of acute skeletal and cardiac muscle \\ injuries in amateur triathletes
}

$\begin{aligned} \text { Maria Fátima Glaner } & { }^{1} \\ \text { William Alves Lima } & { }^{1} \\ \text { Luiz Carlos C. Jovita } & \end{aligned}$

1 Universidade Católica de Brasília. Programa de Pós-Graduação Stricto Sensu em Educação Física. Brasília, DF. Brasil.

2 Hospital Regional da Ceilândia. Núcleo de Patologia Clínica. Brasília, DF. Brasil.

Recebido em 06/05/08 Revisado em 13/07/08 Aprovado em 15/11/08
Resumo - A creatina quinase (CK) e a sua fração músculo-cérebro (CK MB) podem estar ligadas a danos no tecido muscular e cardíaco, respectivamente, como conseqüência de exercícios prolongados e intensos. $\mathrm{O}$ estudo teve como objetivo verificar se a variação aguda da $\mathrm{CK}$ e da $\mathrm{CK} \mathrm{MB}$ reflete algum risco de desgaste acentuado para a musculatura esquelética e cardíaca, de atletas amadores, após o Ironman 70.3. A amostra foi composta por dez atletas voluntários, masculinos (idade $=34,0 \pm 9,2$ anos). A amostra de sangue venoso $(2 \mathrm{~mL})$ foi coletada antes e após o Ironman 70.3. Os voluntários completaram o percurso em 5 h20 min à 6 h. A CK e a CK MB foram analisadas pelo método enzimático, usando reagentes Wienner lab®, em um espectrofotômetro automático (Targa bt $3000 \AA)$ ). O teste não paramétrico de Wilcoxon indicou diferenças significativas $(p<0,05)$ entre os períodos pré e pós competição nas variáveis estudadas. Os valores médios foram: $\mathrm{CK}=112,23 \pm 34,9 \mathrm{U} / \mathrm{L}$ e $458,0 \pm 204,9 \mathrm{U} / \mathrm{L}(\Delta \%=418,2) ; \mathrm{CK} M B=7,4 \pm 2,6 \mathrm{U} / \mathrm{L}$ e $10,8 \pm 3,9 \mathrm{U} / \mathrm{L}(\Delta \%=153,3)$, respectivamente, para pré e pós. A variação relativa da CK MB em relação à CK, pré $(6,9 \%)$ e pós competição $(2,5 \%)$, indicou que este não é um fator tão preocupante durante o exercício extenuante de longa duração, como o Ironman 70.3. Conclui-se que a concentração aguda de CK, logo após o término do exercício extenuante de longa duração, indicou desgaste da musculatura esquelética, porém considerado normal para atletas. Quanto à CK MB, o desgaste da musculatura cardíaca foi inexistente.

Palavras-chave Creatina quinase; Fadiga muscular; Esforço físico; Lesões cardíacas, Atleta.

Abstract - Creatine kinase (CK) and creatine kinase muscle-brain fraction (CK-MB) might be associated with damage to muscle and cardiac tissue, respectively, as a consequence of intense prolonged exercise. The objective of the present study was to determine whether acute changes in CK and CK-MB reflect some risk of damage to skeletal and cardiac muscles in amateur athletes after Ironman 70.3. The sample consisted of 10 male athlete volunteers (age: $34.0 \pm 9.2$ years). A venous blood sample $(2 \mathrm{~mL})$ was collected before and after the competition. The volunteers completed the race in $5 \mathrm{~h} 20 \mathrm{~min}$ to $6 \mathrm{~h}$. CK and CK-MB were analyzed by an enzymatic method using Wiener lab $₫$ reagent in an automatic spectrophotometer (Targa bt $3000 \AA)$. The nonparametric Wilcoxon test showed significant differences $(p<.05)$ in the variables studied before and after the competition. Mean CK was $112.23 \pm 34.9$ and $458.0 \pm 204.9 \mathrm{U} / \mathrm{L}(\Delta \%=418.2)$, and mean $\mathrm{CK}-\mathrm{MB}$ was $7.4 \pm 2.6$ and $10.8 \pm 3.9 \mathrm{U} / \mathrm{L}(\Delta \%=153.3)$ before and after the event, respectively. The relative variation in CK-MB compared to CK before (6.9\%) and after (2.5\%) the competition showed that the former is not a factor of concern during intense prolonged exercise such as Ironman 70.3. In conclusion, the acute increase in $\mathrm{CK}$ after the end of intense prolonged exercise indicates skeletal muscle damage which, however, is considered to be normal for athletes. With respect to CK-MB, cardiac muscle injury was inexistent.

Key words: Creatine kinase; Muscle fatigue; Exertion; Heart injuries; Athlete. 


\section{INTRODUÇÃO}

O triathlon é uma modalidade que consiste na junção de três provas, natação, ciclismo e corrida, nesta respectiva ordem. Esta modalidade surgiu na década de 70 e vem ganhando grande popularidade, principalmente, após sua estréia nas olimpíadas de Sidney no ano 2000¹. A competição mais importante é conhecida como Ironman, na qual os atletas nadam por uma distância de 3,8 km, pedalam $180 \mathrm{~km}$ e correm $42,195 \mathrm{~km}$ de forma ininterrupta. Uma variação desta modalidade que vem ganhando grande popularidade é conhecida como Ironman 70.3 . O número 70.3 se refere à metade da distância de um Ironman, em milhas.

Nas três provas do Ironman 70.3, os mesmos grupamentos musculares são recrutados em ângulos e intensidades distintos. Portanto, a carga aplicada em cada músculo atinge as fibras musculares em intensidades diferentes ${ }^{1}$. Consequentemente, há uma maior chance de que, mais fibras de um mesmo músculo sejam lesionadas e, mais creatina quinase seja liberada para a corrente sangüínea.

Elevações nas concentrações sangüíneas de creatina quinase são indicativos de um aumento na permeabilidade da membrana, o que representa a carência de substrato energético para a célula, acarretando em uma diminuição do poder de contração. À medida que um maior número de células deixa de atuar, as demais serão sobrecarregadas e, a lesão tecidual vai progredindo $^{2}$. Em conseqüência, inicia-se a regeneração muscular, com uma reação inflamatória que pode se manifestar de zero à $24 \mathrm{~h}$ após o trauma ${ }^{3}$.

Como os atletas geralmente não podem ficar três dias de repouso para cada sessão de treino mais intenso, faz-se necessário um monitoramento periódico com o intuito de prevenir lesões teciduais crônicas, que podem, além de reduzir o desempenho, ainda ocasionar uma queda funcional no sistema imunológico e levar a um estado de "sobre-treinamento"4.

Uma das melhores formas de medir o desgaste muscular é através da quantificação da creatina quinase (CK). Esta enzima é encontrada predominantemente dentro da fibra muscular e, somente tem sua concentração aumentada na circulação sangüínea em casos de lesão tecidual. Tal lesão pode ser provocada pelo estresse gerado no esforço físico extenuante prolongado ou, pela compressão tecidual decorrente de choques mecânicos ${ }^{5}$.

A fração $\mathrm{CK}$ músculo-cérebro (CK MB) encontra-se principalmente no músculo cardíaco ${ }^{6}$. Um aumento da sua fração é um indicativo de que houve um grande desgaste da musculatura cardíaca e, dependendo das condições clinicas da pessoa, pode representar um risco de ocorrência de um infarto do miocárdio ${ }^{7,8}$. Esforços físicos extenuantes prolongados sempre geram um desgaste cardíaco proporcional ao quanto à musculatura está adaptada a sustentar níveis específicos de contração. Em indivíduos menos treinados, o suprimento de oxigênio e substratos energéticos transportados pelo sangue, pode não ser suficiente para abastecer tanto a musculatura esquelética quanto a própria musculatura cardíaca, em conseqüência, ocorre um aumento do trabalho cardíaco, ocasionando fadiga e lesão tecidual ${ }^{4,7}$.

Com o intuito de verificar o desgaste muscular, após sessões de treino ou competições, pesquisadores ${ }^{2,9,10}$ têm mensurado as concentrações de CK e da sua fração MB, em atletas de alto nível. Nesta perspectiva, o objetivo deste estudo foi verificar se a variação aguda da CK e da sua fração $\mathrm{MB}$ refletem algum risco de desgaste acentuado para a musculatura esquelética e cardíaca de atletas amadores, depois de completada uma prova do Ironman 70.3.

\section{PROCEDIMENTOS METODOLÓGICOS}

A amostra foi composta por atletas amadores do Ironman 70.3, Brasília-DF. Os sujeitos foram convidados a participar do estudo um dia antes da competição, durante o Congresso Técnico. Voluntariaram-se 13 atletas, no entanto, a amostra final foi composta por 10 atletas. Três atletas, por motivos particulares, não compareceram após a competição para realizar as devidas coletas/mensurações.

\section{Procedimentos para a coleta de dados}

No Congresso Técnico da competição, foram esclarecidos os objetivos do estudo e como seria feita a coleta de dados. No dia da competição, à medida que os atletas chegavam ao local da prova, foram novamente convidados a participar da coleta de dados pré e pós competição.

Todos os voluntários assinaram um termo de consentimento livre e esclarecido, que lhes garantia o total anonimato e sigilo quanto aos resultados individuais. Também lhes dava o 
direito de desistir da participação na pesquisa a qualquer instante, sem qualquer recriminação por parte dos pesquisadores, como exigem as normas éticas da resolução ${ }^{11}$ n . 196/out., 1996.

Durante todo o percurso da prova, todos os voluntários tiveram livre acesso ao consumo de água, repositores hidroeletrolíticos, bebidas glicosadas e comidas (ex: pão, banana, glicogel). Nenhum dos fatores relacionados à alimentação foi controlado, uma vez que estes não interferem nas concentrações sangüíneas de CK.

\section{Variáveis mensuradas}

$\mathrm{Na}$ coleta pré-competição, além da coleta sangüínea, foram mensuradas a estatura e a massa corporal ${ }^{12}$. A gordura corporal relativa foi estimada pela técnica da impedância bioelétrica (Biodynamics 310), sendo seguidas todas as instruções do manual do referido equipamento.

A coleta sangüínea foi feita por uma enfermeira graduada (COREN-GO 152370) e habituada a tal procedimento. Durante a coleta, os voluntários permaneceram sentados, com o braço apoiado sobre um suporte. Em seguida, tiveram seu braço garroteado, aproximadamente, no ponto médio do úmero e feita a anti-sepsia do local da coleta com algodão embebido em álcool.

Com a ajuda de um adaptador de agulhas para coletas múltiplas, foi introduzida uma agulha descartável de $25 \times 8 \mathrm{~mm}$ em uma das veias da fossa antecubital do braço. Aproximadamente, $2 \mathrm{~mL}$ de sangue foram coletados em um tubo (Bencton Dickinson) a vácuo com EDTA. Estes tubos foram colocados em uma caixa térmica com gelo, para depois serem levados ao laboratório onde o sangue foi centrifugado (Centrifuga Celm - LS-3 Plus) no máximo 2h depois da sua coleta. A centrifugação foi feita durante $15 \mathrm{~min}$ a $3200 \mathrm{rpm}$. Depois de separado o plasma, este foi armazenado, por uma semana, a uma temperatura entre $0^{\circ}$ e $4^{\circ} \mathrm{C}$.

Os mesmos procedimentos de coleta sangüínea foram repetidos, no máximo, $20 \mathrm{~min}$ depois de concluída a última prova da competição.

A análise sangüínea foi procedida pelo método enzimático através de um auto-analisador bioquímico Targa bt $3000^{\circledR}$. Os reagentes bioquímicos adotados foram da marca Wienner $l a b^{\circledR}$. Foram seguidos todos os procedimentos descritos pelos fabricantes do auto-analisador e dos reagentes.

Cada amostra de sangue passou duas vezes pelo auto-analisador e, em caso de não haver equi- valência de medida (variação de até $5 \mathrm{U} / \mathrm{L}$ ) seria realizada uma terceira análise, o que não foi o caso. Foram usados os dados da primeira análise.

Para a análise estatística foi realizado o teste não paramétrico de Wilcoxon $(\mathrm{p}<0,05)$ para comparar as concentrações de CK e sua fração $\mathrm{MB}$, pré e pós competição. A caixa de bigodes foi usada para comparar a variação relativa da CK MB pré e após a competição, em relação aos respectivos valores de CK. O programa utilizado foi o SPSS (Statistical Package for the Social Sciences), versão 14.0.

\section{RESULTADOS}

Os atletas compuseram uma amostra heterogênea em relação à idade, massa corporal, estatura e gordura corporal relativa, como está demonstrado na Tabela 1.

Tabela 1. Características da amostra quanto à idade, antropometria e gordura corporal relativa $(n=10)$.

\begin{tabular}{lcc}
\hline Variáveis & $\overline{\mathrm{X}}$ & Amplitude \\
\hline Idade $_{(\text {anos) }}$ & $34,0 \pm 9,2$ & $21-48$ \\
Massa corporal $_{(\mathrm{kg})}$ & $74,9 \pm 9,8$ & $60,1-94,1$ \\
Estatura $_{(\mathrm{cm})}$ & $175,9 \pm 8,1$ & $165,0-189,0$ \\
\%gordura & $14,7 \pm 2,7$ & $11,2-18,2$ \\
\hline
\end{tabular}

A CK teve a sua concentração aumentada em $418,2 \%$ e CK MB em 153,3\%. Ambas as variáveis tiveram aumento estatisticamente significativo $(p<0,05)$, conforme detalhado na Tabela 2. A variação relativa CK MB em relação à $\mathrm{CK}$, pré $(6,9 \%)$ e pós $(2,5 \%)$ competição, é ilustrada na Figura 1.

Tabela 2. Comparação da creatina quinase e sua fração $M B$, pré e pós-competição $(n=10)$.

\begin{tabular}{lccccc}
\hline Variáveis & Pré & $\begin{array}{c}\text { Ampli- } \\
\text { tude }\end{array}$ & Pós & $\begin{array}{c}\text { Ampli- } \\
\text { tude }\end{array}$ & $\Delta \%$ \\
\hline CK $_{(\mathrm{U} / \mathrm{L})}$ & $112,2 \pm$ & $68,2-$ & $458,2 \pm$ & $265,0-$ & \\
& 34,9 & 174,0 & $204,9 \mathrm{a}$ & 938,0 & 418,2 \\
$\mathrm{CK} \mathrm{MB}_{(\mathrm{U} / \mathrm{L})}$ & $7,4 \pm$ & $3,5-$ & $10,8 \pm$ & $6,0-$ & 153,3 \\
& 2,6 & 11,5 & $3,9 a$ & 16,7 & \\
\hline
\end{tabular}

Sendo: $\Delta \%=$ variação relativa média; $C K=$ creatina quinase; ${ }^{a}=p \leq 0,05 ; M B=$ fração da enzima CK referente à musculatura estriada cardíaca.

\section{DISCUSSÃO}

O propósito deste estudo foi verificar se a variação aguda da $\mathrm{CK}$ e sua fração $\mathrm{MB}$ refletem algum risco de desgaste acentuado sobre a 


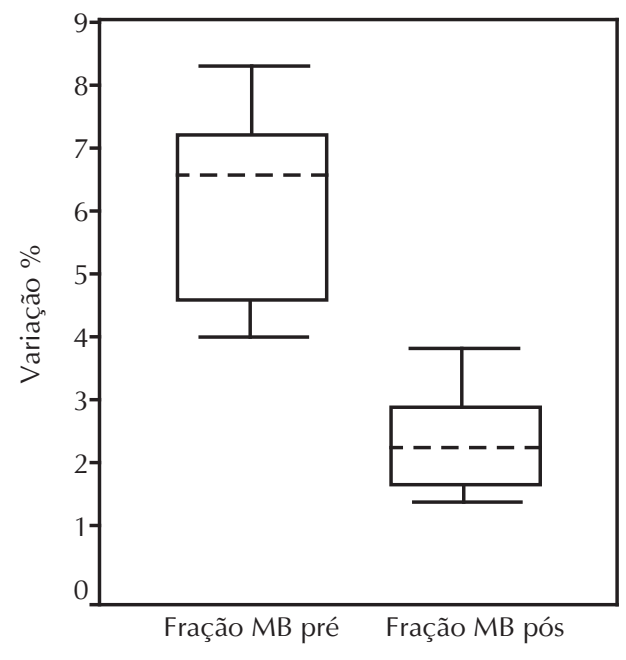

Figura 1. Variação relativa (\%) da fração creatina quinase (CK) músculo-cérebro $(\mathrm{MB})$ em relação à $\mathrm{CK}$, pré e pós competição. As bases inferior ( $1^{\circ}$ Quartil) e superior ( $3^{\circ}$ Quartil) dos retângulos indicam os respectivos quartis. As linhas pontilhadas indicam o $2^{\circ}$ Quartil (mediana). Os prolongamentos $(\perp \mathrm{T})$ indicam os valores mínimos máximos.

musculatura esquelética e cardíaca, respectivamente, depois de completado o percurso do Ironman 70.3. Os 10 atletas amadores levaram entre $5 \mathrm{~h} 20 \mathrm{~min}$ e $6 \mathrm{~h}$ para completar o percurso. Aproximadamente, a natação ocupou cerca de $18 \%$ do tempo total da competição, o ciclismo $50 \%$ e a corrida $32 \%$.

As concentrações iniciais de CK estavam, em média, antes do início da prova, dentro da faixa de concentração de referência, tanto

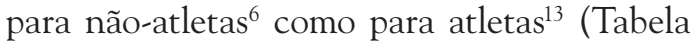
1). Para a $\mathrm{CK} M B$, as concentrações abaixo de $25 \mathrm{U} / \mathrm{L}$ são consideradas aceitáveis ${ }^{6}$. Isto indica a ausência de lesões que sejam relevantes na musculatura esquelética e cardíaca, respectivamente.

Após a competição, os atletas apresentaram valores absolutos de $\mathrm{CK}$ e CK MB sensivelmente superiores $(\mathrm{p}<0,05)$ aos valores apresentados antes do início da competição.

Quanto a CK, apesar dos valores estarem acima do limite superior aceitável para nãoatletas, os atletas não apresentaram lesão tecidual acentuada. Haja vista que, para atletas, os valores de referência ${ }^{13}$ podem oscilar de 881 a 1474U/L (limite superior).

No entanto, como a CK aumentou 418,2\% imediatamente após a prova e como seu pico máximo ocorre entre 24 e $72 \mathrm{~h}$ após o esforço ${ }^{4,6}$, a lesão tecidual pode ter sido mais acentuada a posteriori. Pois, em recente estudo ${ }^{14}$ feito em triatletas amadores, foi encontrado um pico de 300\% da CK, após esforço de longa duração. Em tais circunstâncias, se atletas não fizerem o monitoramento da CK e realizarem treinamentos intensos e prolongados, poderão apresentar uma diminuição no sistema imunológico e entrar em "sobre-treinamento" 4

Em um estudo ${ }^{10}$ semelhante a este, foram medidos nove atletas experientes em Ironman 70.3. Foram obtidos os seguintes valores para a CK, antes e logo após a competição, respectivamente, $199 \pm 93 \mathrm{U} / \mathrm{L}$ e $713 \pm 406 \mathrm{U} / \mathrm{L}$.

A concentração para a CK no estudo de Welsh et al. ${ }^{10}$ foi maior que a encontrada no presente estudo. $O$ fato dos atletas do estudo citado $^{10}$ serem experientes na modalidade em questão e os aqui estudados serem amadores, pode ter contribuído para estas discrepâncias. Quanto maior o nível de desempenho, menores são as concentrações de $\mathrm{CK}^{13}$. A maior intensidade (menor tempo) imposta para concluir a prova $^{10}$, a qual se reflete no desgaste muscular, também pode ter contribuído para tal.

Por outro lado, para exercícios classificados como de endurance, podem existir "bons" respondedores e "maus" respondedores à forma aguda ${ }^{15}$. Geralmente, pessoas com maior tempo de treinamento apresentam uma menor liberação de CK para a corrente sangüínea, porque possuem uma melhor mecânica de movimento e uma maior adaptação da fibra muscular esquelética ao tipo de contração realizada. Já os indivíduos com maior percentual de gordura, tendem a ter um maior desgaste da fibra por estarem carregando uma maior sobrecarga ${ }^{2}$.

Pazikas et al. ${ }^{9}$ mensuraram a CK de duas atletas de nado sincronizado após 3h18min de treino preparatório para as Olimpíadas de Atenas. Não encontraram diferença $(\mathrm{p} \geq 0,05)$ para esta variável logo após o término do treino. Talvez este fato tenha ocorrido por ser uma prática sem impacto, além do fato das atletas já estarem no ápice do seu desempenho, o que minimiza as elevações nas concentrações da CK. Analisando estes dados ${ }^{9}$ em relação aos obtidos no presente estudo, fica evidente que o desgaste muscular em uma prova de triathlon é muito superior ao de outras modalidades. Também aponta que, o fato de uma sessão de treino ter duração prolongada, por si só, não é suficiente para provocar desgaste muscular.

Apesar da CK MB ter aumentado 153,3\% (Tabela 2), a variação desta em relação CK total (Figura 1) aponta que não houve dano à musculatura cardíaca, pré e pós competição. 
Isto indica que a prova Ironman 70.3 gerou nos atletas um desgaste cardíaco proporcional ao quanto a musculatura deles está adaptada a sustentar níveis específicos de contração ${ }^{4,7}$. Em condições de repouso, CK MB pode corresponder de 15 a $20 \%$ da $\mathrm{CK}^{16}$. Para condições de esforço físico extenuante, a variação relativa $\mathrm{CK} \mathrm{MB}$ em relação à $\mathrm{CK}$ deve estar entre zero e $5 \%{ }^{17}$. Desta forma, observa-se que o risco de lesão cardíaca é inexistente nos dois momentos analisados. Resultados semelhantes foram obtidos em outros estudos ${ }^{2,18,19}$.

Em atletas experientes em Ironman 70.3, antes e após a competição, foi obtido ${ }^{10} 6,7 \pm 2,9$ e $28,1 \pm 21,7 \mathrm{U} / \mathrm{L}$, respectivamente. Adicionalmente a estas análises, as concentrações de troponina e ecocardiografias, pré e pós competição, indicaram que, apesar do desgaste da musculatura esquelética, não houve desgaste cardíaco acentuado. Isto, aliado ao obtido no presente estudo e ao estudo de Totsuka et al. ${ }^{2}$ converge à afirmativa de que exercícios extenuantes de endurance, por si só, não induzem danos à musculatura cardíaca de indivíduos fisicamente treinados.

Os desvios padrões indicam grande heterogeneidade da amostra, tanto em relação à CK quanto à CK MB. A existência de "bons" e "maus" respondedores às respostas agudas de exercícios de endurance extenuantes ${ }^{15}$, as fases de treinamento, dentre outros, podem ter provocado esta variabilidade no grupo. Desta forma, torna-se importante realizar monitoramentos periódicos, posteriores as competições, ou mesociclos de treinamento mais desgastantes. Isto possibilita avaliar o desgaste muscular gerado pelo esforço e também, adequar as cargas de treinamento das sessões seguintes, de forma a prevenir uma progressão das lesões musculares, assim como um possível estado de "sobre-treinamento".

No contexto que este estudo foi desenvolvido, duas são as limitações principais. Uma, a não realização de análises da CK 24, 48 e 72h após a competição, haja vista o pico de concentração ocorrer 24-72h após o esforço físico ${ }^{6}$. A outra foi a impossibilidade de padronizar o treinamento dos atletas nos três dias que antecederam a competição. Um possível treinamento mais intenso pode ter contribuído para a ocorrência de algumas concentrações mais elevadas de CK. Estas limitações foram inevitáveis, pois a maioria dos atletas não reside no local onde aconteceu a competição (Brasília - DF). No entanto, estas limitações não diminuem a importância dos achados do presente estudo, haja vista que o objetivo foi avaliar atletas amadores em uma situação real de competição, na qual o empenho e a motivação são sensivelmente maiores do que no treino.

\section{CONCLUSÃO}

As concentrações agudas de CK total se elevam de forma extremamente significativa imediatamente após o término do esforço extenuante de longa duração, indicando desgaste na musculatura esquelética, porém considerado normal para atletas. Quanto à CK MB, sua concentração logo após o esforço físico indica que não ocorreu o desgaste da musculatura cardíaca. Sendo este, então, um fator menos preocupante durante o esforço extenuante de longa duração, como o Ironman 70.3. No entanto, cada atleta deve ser avaliado somente em relação a ele mesmo, uma vez que existem "bons" e "maus" respondedores de forma aguda.

\section{REFERÊNCIAS BIBLIOGRÁFICAS}

1. Lopes RF. Comportamento de alguns marcadores fisiológicos e bioquímicos de uma prova de triathlon olímpico. [Dissertação de Mestrado - Programa de Pós-Graduação em Educação Física]. Curitiba (PR): Universidade Federal do Paraná; 2006.

2. Totsuka M, Nakaji S, Suzuki K, Sugawara K, Sato K. Break point of serum creatine kinase release after endurance exercise. J Appl Physiol 2002;93(4):1280-1286.

3. Noonan TJ, Garrett WE. Muscle strain injury: diagnosis and treatment. J Am Acad Orthop Surg 1999; 7(4):262-269.

4. Lehmann M, Gastmann U, Petersen KG, Bachl N, Seidel A, Khalaf AN, Fisher S, Keul J. Trainingovertraining: performance, and hormone levels, after a defined increase in training volume versus intensity in experienced middle- and long-distance runners. Br J Sports Med 1992;26(4):233-242.

5. Brancaccio $P$, Maffulli N, Limongelli FM. Creatine kinase monitoring in sport medicine. Br Med Bull 2007;81-82(1):209-230.

6. Wyss M, Kaddurah-daouk R. Creatine and creatinine metabolism. Physiological Reviews 2000;80(3):1107-1113.

7. Varat MA, Mercer DW. Cardiac specific creatine phosphokinase isoenzyme in the diagnostic of acute myocardial infarction. Circulation 1975;51(5):855-9.

8. Camarozano ACA, Henriques LMG. Uma macromolécula capaz de alterar o resultado da CK-MB e induzir ao erro no diagnóstico de infarto agudo do miocárdio. Arq Bras Cardiol 1996;66(3):143-147. 
9. Pazikas MGA, Curi A, Aoki MS. Comportamento de variáveis fisiológicas em atletas de nado sincronizado durante uma sessão de treinamento na fase de preparação para as olimpíadas de Atenas 2004. Rev Bras Med Esporte 2005;11(6):357-362.

10. Welsh RC, Warburton DER, Humen DP, Taylor DA, McGavock J, Haykowsky MJ. Prolonged strenuous exercise alters the cardiovascular response to dobutamine stimulation in male athletes. J Physiol 2005;569(1):525-30.

11. Conselho Nacional de Saúde. Resolução CNS 196/96. Available from: http://conselho.saude. gov.br/comissao/conep/atribuicoes.html [2004 nov 23].

12. Petroski EL. Antropometria: técnicas e padronizações. 2 ed. Porto Alegre: Palotti, 2003.

13. Mougios V. Reference intervals for serum creatine kinase in athletes. Br J Sports Med 2007;419(10):674-678.

14. Bessa A, Nissembaum M, Monteiro NA, Gandra PG, Nunes LAS, Bassini-Cameron A, et al. High intensity ultraendurance promotes early release of muscle injury markers. Br J Sports Med 2008;42(11):589-593.

15. Newham DJ, Jones DA, Edwards RH. Large delayed plasma creatine kinase changes after stepping exercise. Muscle Nerve 1983;6(5):380-385.

16. Hossein-Nia M, Kallis P, Brown PA, Chester MR, KasKi JC, Murday AJ, Treasure T, Holt DW. Creatine kinase $\mathrm{MB}$ isoforms: sensitive markers of ischemic myocardial damage. Clin Chem 1994;40(7):1265-1271.
17. Douglas PS, O’Toole ML, Hiller DB, Hackney K, Reychek N. Cardiac fatigue after prolonged exercise. Circulation 1987;76(6):1206-1213.

18. Shave R, Dawson E, Whyte G, Gerorge K, Gaze D, Collinson P. Altered cardiac function and minimal cardiac damage during prolonged exercise. Med Sci Sports Exerc 2004;36(7):1098-1103.

19. La Gerche A, Boyle A, Wilson AM, Prior DL. No evidence of sustained myocardial injury following an Ironman distance triathlon. Int J Sports Med 2004;25(1):45-49.

\author{
Endereço para correspondência \\ Maria Fátima Glaner \\ Universidade Católica de Brasília \\ Programa de Pós-Graduação Strictu Sensu em \\ Educação Física \\ Campus I - QS 07 Lote 01, EPCT \\ 71966-700 - Águas Claras. Brasília - DF \\ E-mail: mfglaner@ucb.br \\ mfglaner@gmail.com
}

